
\title{
$\angle$ Research Square \\ 2D PdCu Alloy Nanodendrites Manifest Effective Peroxidase-Like Activity Against Biofilms
}

\section{Guotao Yuan}

Soochow University

\section{Shitong Zhang}

Soochow University

\section{Zaixing Yang}

Soochow University

Xin Tian

Soochow University

\section{Si Cheng}

Soochow University

Yue Pan ( $\nabla$ panyue@mail.sysu.edu.cn )

Sun Yat-Sen University https://orcid.org/0000-0001-7709-0508

\section{Ruhong Zhou}

Columbia University

\section{Research}

Keywords: PdCu alloy, 2D nanodendrites, peroxidase-like activity, density functional theory, biofilm, increasing resistance

Posted Date: December 29th, 2021

DOI: https://doi.org/10.21203/rs.3.rs-1162314/v1

License: (c) (1) This work is licensed under a Creative Commons Attribution 4.0 International License. Read Full License 


\section{Abstract}

Noble metal nanomaterials with peroxidase-like catalytic activity have received great interest lately for their potential applications in biomedicine and environmental protection; however, it is still challenging to achieve high catalytic efficiency despite enormous efforts. In this work, a novel but simple route was developed to synthesize 2D PdCu alloy nanodendrites (PdCu NDs) as a high-performance peroxidase mimic for biofilm elimination. Catalytic kinetics shows that the composition-dependent synergy between $\mathrm{Pd}$ and $\mathrm{Cu}$ in the PdCu NDs can strongly enhance the peroxidase-like activity. Density functional theory calculations further provide the underlying mechanisms at both atomic and electronic levels for the effective adsorption and dissociation of $\mathrm{H}_{2} \mathrm{O}_{2}$ molecules on $\mathrm{PdCu}$ NDs surfaces. Owing to their superior peroxidase-like activity, the PdCu NDs exhibit striking biofilm inhibition properties, which suggests that the controlled synthesis of 2D noble metal alloy may open up new opportunities for enhancing enzymelike activities of noble metal nanomaterials.

\section{Introduction}

Infections induced by biofilm-forming bacteria have emerged as a severe public health threat around the world due to their increasing resistance against different antibiotics. ${ }^{1-3}$ The bacteria in the biofilm state have increased resistance to antibiotics, disinfectants, heat stress, $\mathrm{pH}$, and immunity, which is one of the main reasons for the difficulties in the treatment of biofilm infection. ${ }^{4}$ For example, the opportunistic pathogen Pseudomonas aeruginosa ( $P$. aeruginosa) is one of the leading causes of nosocomial infection, ${ }^{5}$ because the formed biofilm makes it extremely difficult to eradicate $P$. aeruginosa thoroughly. ${ }^{6}$ Therefore, it is of urgent need to develop highly efficient antibacterial agents with unique inhibition mechanism to defeat the biofilm without inducing significant resistance.

Meanwhile, a wide variety of nanomaterials have been proposed/developed as promising antibacterial agents, such as silver nanomaterials, ${ }^{7}$ copper nanomaterials, ${ }^{8}$ and graphene oxide, ${ }^{9}$ owing to the rapid development of nanotechnology. However, these nanomaterials have achieved limited success in antibiofilms, primarily due to their not-high-enough catalytic activities. In recent years, nanomaterials with intrinsic enzyme-like catalytic activities (also known as nanozymes) have attracted great attention because of their high catalytic activities and high stability (and low cost). ${ }^{10-12}$ Given these advantages, nanozymes have shown great potential in a broad range of applications including biological detection, ${ }^{13}$, ${ }^{14}$ cancer treatment, ${ }^{15,16}$ and antibacterial agent. ${ }^{17,18}$ Previous studies have demonstrated that $\mathrm{Pd}$ nanozymes are good candidates for antibacterial application because of their high catalytic activity and good biocompatibility. ${ }^{19,20}$ For instance, our group found in an earlier study that Pd nanomaterials with peroxidase-like activity exhibit excellent antibacterial effects without producing significant toxicity to human cells, which can be used as new antibacterial agents. ${ }^{21}$ Nonetheless, there is still much work to do to improve the catalytic activity of Pd nanomaterials as antibacterial agents, particularly for anti-biofilms. To the best of our knowledge, few reports have provided 2D Pd-based nanomaterials with enzyme-like catalytic activity for biofilm elimination so far. 
In order to further improve the catalytic activity of Pd nanomaterials, one feasible strategy is to tune their composition $^{22}$ and structure ${ }^{23}$. Many reports have revealed that the enzyme-like activities of $\mathrm{Pd}$ nanomaterials can be enhanced by a combination of $\mathrm{Pd}$ with other metals (eg. $\mathrm{Au}^{24}{ }^{24} \mathrm{Pt}^{25} \mathrm{Ir}^{26}$ ) to form alloy nanostructures. For instance, depositing Ir atoms as ultrathin shells on Pd nanocubes significantly enhanced the peroxidase-like efficiency compared with the original Pd nanocubes. ${ }^{26}$ Moreover, it was demonstrated that two-dimensional (2D) Pd-based nanomaterials display superior catalytic activities over commercial Pd black catalysts under similar conditions, due to the high surface-area-to-volume ratio and thus high density of exposed atoms on the surface of $2 \mathrm{D}$ nanomaterials. ${ }^{27,28}$ Very recently, Zhang and coworkers fabricated PdCu alloy nanosheets, which exhibit much higher electrocatalytic activity than those of Pd-based catalysts in formic acid oxidation. ${ }^{29}$ However, despite PdCu alloy nanosheets' good catalytic activity, their synthetic process was complicated. They were synthesized in the oil phase, which makes them difficult to be directly applied in biomedical applications. Meanwhile, 2D alloy nanodendrites with high structural anisotropy and specific surface areas possess extensive undercoordinated sites, which can supply a natural dendrite-like framework for the study of defect engineering. ${ }^{30}$ However, the stringency of their preparing process, originated from the thermodynamically unfavorable (and mostly kinetical driven) ramification process within the $2 D$, suppress somewhat the promise for catalytic applications. ${ }^{31}$ As a result, a better and more straightforward preparation of $2 \mathrm{D}$ dendrite-like alloy is highly desired, though very challenging.

In this study, we developed a novel but simple method to synthesize 2D PdCu alloy nanomaterials with dendrite-like morphology (PdCu NDs) in aqueous solution under mild conditions for biofilm elimination. Our experiments show that PdCu NDs mimic peroxidase and the peroxidase-like activity of PdCu NDs can be effectively regulated by varying $\mathrm{Pd} / \mathrm{Cu}$ ratio. Density functional theory (DFT) calculations reveal atomic and electronic details on how $\mathrm{Pd} / \mathrm{Cu}$ ratio affects the catalytic property of $\mathrm{PdCu}$ NDs. Furthermore, we show that PdCu NDs with intrinsic peroxidase-like acticity exert a strong anti-biofilm acticity.

\section{Results And Discussion}

\section{Preparation and characterization of the PdCu NDs}

The PdCu NDs were synthesized by the coreduction of $\mathrm{Pd}$ and $\mathrm{Cu}$ precursors in aqueous solution with the presence of octadecyltrimethylammonium chloride (OTAC) at $10^{\circ} \mathrm{C}$ (see Supporting information for more details). This novel method has two advantages: (1) the reaction condition is mild and environmentally friendly; (2) the products can be easily dispersed in water, which is favorable for biomedical applications. The crystal structure of the obtained PdCu NDs was analyzed firstly by X-ray powder diffraction (XRD). As shown in Fig. 1a, XRD pattern supports the formation of PdCu alloy structures. The diffraction peaks of the products were between the corresponding peaks of pure $\mathrm{Pd}$ and $\mathrm{Cu}$, indicating the formation of $\mathrm{PdCu}$

alloy structures rather than phase separation. ${ }^{31}$ According to the transmission electron microscopy (TEM) images, the lateral size of the as-synthesized PdCu NDs are around $50 \mathrm{~nm}$ and a dendrite-like structure with an obvious center and branched margins were observed (Fig. 1b and c). The high resolution TEM 
(HRTEM) image and selected area electron diffraction (SAED) pattern of PdCu NDs exhibited clear lattice pattern, where a typical lattice spacing of $2.1 \AA$ was observed in accordance with that of lattice spacing of PdCu alloy (111 facet), suggesting a certain well-defined crystal structure of PdCu NDs (Fig. 1d). Moreover, high-angle annular dark-field scanning TEM (HAADF-STEM) together with energy dispersive Xray spectroscopy mapping (EDX) disclosed that $\mathrm{Pd}$ (red) and $\mathrm{Cu}$ (yellow) distribute homogeneously in the nanocrystals, confirming the successful formation of PdCu NDs (Fig. 1e). The thickness of the PdCu NDs was measured by atomic force microscopy (AFM). From a random height profile across the nanocrystals, we found that PdCu NDs exhibited 2D structure with an average thickness of $\approx 7 \mathrm{~nm}$ (Fig. 1f).

Next, the molar ratio of Pd and Cu precursors was further varied to explore and optimize the catalytic activity of the synthesized PdCu NDs. It was found that pure $\mathrm{H}_{2} \mathrm{PdCl}_{4}$ formed $\mathrm{Pd}$ nanoparticles composed of two-dimensional slices (Fig. 2a). The typical 2D PdCu NDs were obtained when the molar ratio of Pd to Cu precursors increased to 20:6 (Fig. 2c). Additionally, when the molar ratio of Pd to Cu precursors increased from 20:6 to 20:15, the nanodendrite-like PdCu nanostructures had no significant change (Fig. 2c-f). Inductively coupled plasma optical emission spectrometry (ICP-OES) analysis demonstrated that the molar ratios in the PdCu nanostructures were $11.8,10.2,9.2,8.1$ and 7 when the molar ratios of Pd to Cu precursors were 20:3, 20:6, 20:9, 20:12, and 20:15, respectively (Fig. 2b-f).

\section{Peroxidase-like property of the PdCu NDs}

Considering their unique structure and morphology, the PdCu NDs can be used as enzyme mimics for catalysis of substrates. The peroxidase-like activity of Pd nanoparticles and various PdCu NDs have been assessed by determining their ability to oxidize the commonly used peroxidase substrate 3,3,5,5tetramethylbenzidine (TMB) in the presence of $\mathrm{H}_{2} \mathrm{O}_{2} \cdot \mathrm{H}_{2} \mathrm{O}_{2}$ can be catalyzed by nanozymes to generate $\cdot \mathrm{OH}$ and then oxidize the TMB. As shown in Fig. 3a \& Fig. S1, Pd nanoparticles show good peroxidase-like activity for oxidation of TMB, as evidenced by the time-dependent increment in the maximum absorbance $(652 \mathrm{~nm})$. However, after the introduction of $\mathrm{Cu}$, even at relatively low $\mathrm{Cu}$ content, the oxidizing ability of TMB was significantly enhanced. It was found that the $\mathrm{Pd}_{9.2} \mathrm{Cu}$ NDs exhibit the most effective oxidizing ability of TMB in this case.

We subsequently carried out a steady-state kinetic analysis to quantify the catalytic efficiency of $\mathrm{PdCu}$ nanostructures. Typical Michaelis-Menten kinetics were observed within the suitable range of $\mathrm{H}_{2} \mathrm{O}_{2}$ concentration (Fig. $3 \mathrm{~b}$ ) and a series of kinetic parameters were summarized in Table $\mathbf{S 1}$. It can be seen that the Michaelis constant $\left(K_{\mathrm{m}}\right)$ values of PdCu nanostructures followed a gradual downward trend as the $\mathrm{Cu}$ contents increasing in the nanostructures (Fig. 3c). This indicates that the adsorption affinity of $\mathrm{PdCu}$ nanostructures with $\mathrm{H}_{2} \mathrm{O}_{2}$ can be enhanced by increasing the $\mathrm{Cu}$ content. However, the $k_{\text {cat }}$ value, which measures catalytic efficiency of the catalyst, ${ }^{32}$ showed a volcano-shaped dependence on the $\mathrm{Cu}$ contents, with maximum points corresponding to $\mathrm{Pd}_{9.2} \mathrm{Cu} \mathrm{NDs}$, which is 9-fold higher than that of $\mathrm{Pd}_{7} \mathrm{Cu}$ NDs. As a peroxidase-like nanozyme, $\mathrm{Pd}_{9.2} \mathrm{Cu}$ NDs could catalyze terephthalic acid (TA) into highly fluorescence 2-hydroxy TA (TAOH) in the presence of $\mathrm{H}_{2} \mathrm{O}_{2}$, indicating the formation of $\cdot \mathrm{OH}$ (Fig. 3d). 
Moreover, we found that the catalytic ability of the $\mathrm{Pd}_{9.2} \mathrm{Cu}$ NDs was highly dependent on the $\mathrm{pH}$ and temperature of the reaction system (Fig. S2).

\section{Quantum mechanics calculations on the catalytic activity}

To gain more insight into the catalytic mechanism of PdCu NDs, we then performed density function theory (DFT) calculations to study the adsorption of $\mathrm{H}_{2} \mathrm{O}_{2}$ on PdCu NDs surfaces. As shown in Fig. 4a-f, $\mathrm{H}_{2} \mathrm{O}_{2}$ preferred to be adsorbed at the top site of $\mathrm{Pd}$ with a similar orientation on PdCu NDs surfaces with different Pd/Cu molar ratios (Fig. S3), and the adsorption energy of $\mathrm{H}_{2} \mathrm{O}_{2}$ on the alloy surface gradually decreased (i.e., more favorable) from -4.16 to $-4.25 \mathrm{kcal} \mathrm{mol}^{-1}$, as the Cu content increased. This indicates that the adsorption affinity of $\mathrm{H}_{2} \mathrm{O}_{2}$ can be enhanced by doping more $\mathrm{Cu}$ atoms into Pd crystals, consistent with our experimental findings. Moreover, the values of the adsorption energies, together with the relatively long $\mathrm{H}_{2} \mathrm{O}_{2}$-metal distances ( 3.0 $\AA$ ), suggest that the interaction between $\mathrm{H}_{2} \mathrm{O}_{2}$ and the nanostructure surfaces is mainly contributed by weak non-bonded interactions. Given that the adsorbate, $\mathrm{H}_{2} \mathrm{O}_{2}$, is a polar molecule, we further investigated the charge distribution and electrostatic potential (EP) of the bimetallic system to provide more details into the physisorption of $\mathrm{H}_{2} \mathrm{O}_{2}$. Hirshfeld charge analyses showed that substantial charge transfers occurred from $\mathrm{Cu}$ to $\mathrm{Pd}$ atoms, in agreement with previous calculations and experimental measurements (Fig. S4). ${ }^{33,34}$ Also, as the Cu content increases, the electron transfer between Pd and $\mathrm{Cu}$ becomes more profound in a linear way, leading to greater electrostatic interactions between $\mathrm{H}_{2} \mathrm{O}_{2}$ and $\mathrm{PdCu}$ NDs surface. Fig. $4 \mathrm{~g}$ shows a typical EP distribution of the $\mathrm{H}_{2} \mathrm{O}_{2}$-metal interface: the EP is positive in the region between $\mathrm{H}_{2} \mathrm{O}_{2}$ and the metal surface (region a) and negative in the region away from $\mathrm{H}_{2} \mathrm{O}_{2}$ and the metal surface along the $z$-axis (region $b$ ). By separately scanning the EPs curves of $\mathrm{Pd}_{11.5} \mathrm{Cu}, \mathrm{Pd}_{6.7} \mathrm{Cu}$ and $\mathrm{H}_{2} \mathrm{O}_{2}$ (Fig. S5a), we found that in the region a, the EPs of the isolated $\mathrm{H}_{2} \mathrm{O}_{2}$ and the bimetallic slab are positive (Fig. S5b), and the EP of Pd ${ }_{11.5} \mathrm{Cu}$ is higher than that of $\mathrm{Pd}_{6.7} \mathrm{Cu}$, indicating a greater repulsion of $\mathrm{Pd}_{11.5} \mathrm{Cu}$ to $\mathrm{H}_{2} \mathrm{O}_{2}$. In region $b$, however, it seems the opposite, i.e. EP $\left(\mathrm{Pd}_{11.5} \mathrm{Cu}\right)<\mathrm{EP}\left(\mathrm{Pd}_{6.7} \mathrm{Cu}\right)$, but the $\mathrm{EP}$ of $\mathrm{H}_{2} \mathrm{O}_{2}$ is negative. Therefore, $\mathrm{Pd} 6.7 \mathrm{Cu}$ provides a greater attraction in region $b$ to the adsorbed $\mathrm{H}_{2} \mathrm{O}_{2}$. Taken together, both regions demonstrate a more favorable electrostatic adsorption of the $\mathrm{H}_{2} \mathrm{O}_{2}$ molecule on $\mathrm{Pd}_{6.7} \mathrm{Cu}$ than $\mathrm{Pd}_{11.5} \mathrm{Cu}$ (i.e., the higher the $\mathrm{Cu}$ content, the stronger the adsorption).

The peroxidase-like activity on the metal surface in this study involves the two-step process as below:

\section{$\mathrm{H}_{2} \mathrm{O}_{2}=2 \cdot \mathrm{OH}(1)$}

\section{$2 \cdot \mathrm{OH}=\mathrm{H}_{2} \mathrm{O}+\mathrm{O}(2)$}

According to the previous studies, the homolytic cleavage of $\mathrm{H}_{2} \mathrm{O}_{2}$ (Eq. 1) is the rate-determining step, ${ }^{35}$, 36 and the overall reaction energy $\left(E_{\mathrm{r}}\right)$ can be employed to indicate the peroxidase-like activity: a more negative value of $E_{\mathrm{r}}$ implies a higher peroxidase-like activity. In the lowest-energy adsorption structures 
for the cleaved $\mathrm{H}_{2} \mathrm{O}_{2}$, the produced $\cdot \mathrm{OH}$ preferred to be adsorbed at the bridge site between $\mathrm{Pd}$ and $\mathrm{Cu}$ (Fig. S6). Furthermore, the dissociation (or more precisely, the dissociative chemisorption) of $\mathrm{H}_{2} \mathrm{O}_{2}$ (Eq. 2) showed the most negative $E_{\mathrm{r}}$ value $\left(-39.01 \mathrm{kcal} \mathrm{mol}^{-1}\right)$ on $\mathrm{Pd}_{8.1} \mathrm{Cu}$, as compared with that on other $\mathrm{Pd}-\mathrm{Cu}$ bimetallic systems. The $E_{\mathrm{r}}$ value of the dissociation process on the $\mathrm{Pd}_{7.3} \mathrm{Cu}$ surface $\left(-39.0 \mathrm{kcal} \mathrm{mol}^{-1}\right)$ is only slightly higher. These values indicate that the dissociative chemisorption of the $\mathrm{H}_{2} \mathrm{O}_{2}$ molecule is more favorable on the $\mathrm{PdCu}$ NDs surfaces with a moderate $\mathrm{Pd} / \mathrm{Cu}$ ratio, which might generate the highest peroxidase-like activities. To further shed light on the relationship between $\mathrm{Pd} / \mathrm{Cu}$ ratio and the $E_{\mathrm{r}}$ values, we also calculated the energy of the $d$-band center $\left(\varepsilon_{\mathrm{d}}\right)$ of the bimetallic surfaces referenced to their Fermi level $\left(E_{\mathrm{f}}\right), \varepsilon_{\mathrm{d}}-E_{\mathrm{f}}$. Since the $d$-electrons of transition metals often play a central role in chemisorption of reactants, the $d$-band center $\left(\varepsilon_{\mathrm{d}}-E_{\mathrm{f}}\right)$ for bimetallic surfaces is an effective descriptor to understand the dissociative chemisorption trends for adsorbate: a higher $\varepsilon_{d}-E_{f}$ of the $d$-states usually suggests a more favorable chemisorption for the given adsorbate. ${ }^{37}$ As displayed in Fig. $4 \mathrm{~h}, \mathrm{Pd}_{8.1} \mathrm{Cu}$ and $\mathrm{Pd}_{7.3} \mathrm{Cu}$ have the two highest $\varepsilon_{\mathrm{d}}-E_{\mathrm{f}}$ values, and the curve of $\varepsilon_{\mathrm{d}}-E_{\mathrm{f}}$ displays a good "symmetry" to that of $E_{\mathrm{r}}$, suggesting a strong correlation between the surface $d$-electrons and the dissociative adsorption of the adsorbed $\mathrm{H}_{2} \mathrm{O}_{2}$. The calculated $\varepsilon_{\mathrm{d}}-E_{\mathrm{f}}$ values also suggest that the $d$-electrons of the PdCu NDs surfaces are regulated by the $\mathrm{Cu}$ content in a non-linear way, which explains the highest peroxidase-like activity of the bimetallic system with moderate $\mathrm{Pd} / \mathrm{Cu}$ molar ratio.

\section{Anti-biofilm activity of the PdCu NDs}

Our experimental and theoretical results demonstrate that PdCu NDs exhibit outstanding peroxidase-like activity by efficiently generating $\mathrm{H}_{2} \mathrm{O}_{2}$ species that are subsequently converted into $\cdot \mathrm{OH}$ radicals. The $\cdot \mathrm{OH}$ radicals are highly reactive species that attack most of the organic molecules. They are highly oxidasive in nature which is attributed to their strong catalytic potential. It has been reported that nanozymes with peroxidase-like activity convert $\mathrm{H}_{2} \mathrm{O}_{2}$ into $\cdot \mathrm{OH}$ radicals, which are more toxic to bacteria. ${ }^{18}$ As PdCu NDs induce the significant formation of $\cdot \mathrm{OH}$ radicals, we then examined whether PdCu NDs mediated $\mathrm{H}_{2} \mathrm{O}_{2}$ catalysis can eliminate the embedded bacteria in biofilms. Biofilms were formed using $P$. aeruginosa, a well-established biofilm-forming pathogen. We first investigated the effects of $\mathrm{Pd}_{9.2} \mathrm{Cu} N D s$ (and/or $\mathrm{H}_{2} \mathrm{O}_{2}$ ) on the integrity of biofilms. The extracellular polymeric matrix and bacterial cells were labelled with an Alexa Fluor 647-dextran (in red) and SYTO 9 (in green), respectively. After $72 \mathrm{~h}$ growth, the bacterial cells are densely packed with an extracellular polymeric matrix forming a 3D bacterial structure (biofilm) in the untreated control group (Fig. 5a). Confocal microscopy imaging revealed that treatments with $\mathrm{Pd}_{9.2} \mathrm{Cu}$ $\mathrm{NDs}$ and/or $\mathrm{H}_{2} \mathrm{O}_{2}$ impaired both the accumulation of bacterial cells and the development of extracellular polymeric matrix. According to quantitative image analysis, the thickness of the biofilms decreased from $39 \pm 7 \mu \mathrm{m}$ to around $30 \mu \mathrm{m}$ when treated with $\mathrm{Pd}_{9.2} \mathrm{Cu} \mathrm{NDs}$ or $\mathrm{H}_{2} \mathrm{O}_{2}$ alone; the thickness further decreased to $10 \pm 2 \mu \mathrm{m}$ when treated with both $\mathrm{Pd}_{9.2} \mathrm{Cu}$ NDs and $\mathrm{H}_{2} \mathrm{O}_{2}\left(\mathrm{Pd}_{9.2} \mathrm{Cu} \mathrm{NDs} / \mathrm{H}_{2} \mathrm{O}_{2}\right.$; i.e., $\mathrm{H}_{2} \mathrm{O}_{2}$ were treated immediately after the $\mathrm{Pd}_{9.2} \mathrm{Cu}$ NDs treatment; see Fig. $5 \mathrm{~b}$ ). Also, biofilms were quantitatively evaluated by counting the number of viable bacterial cells (Fig. 5c). Biollms treated with $\mathrm{Pd}_{9.2} \mathrm{Cu} \mathrm{NDs} / \mathrm{H}_{2} \mathrm{O}_{2}$ exhibit an exceptionally strong biocidal effect against $P$. aeruginosa. In contrast, treatments with $\mathrm{Pd}_{9.2} \mathrm{Cu}$ NDs or 
$\mathrm{H}_{2} \mathrm{O}_{2}$ alone had limited antibacterial effects. All these results suggest that $\mathrm{Pd}{ }_{9.2} \mathrm{Cu} N D s / \mathrm{H}_{2} \mathrm{O}_{2}$ is a suitable agent for eliminating biofilms.

\section{Conclusion}

In summary, with a novel but simple synthesis method, 2D PdCu NDs have been successfully prepared via the coreduction of $\mathrm{Pd}$ and $\mathrm{Cu}$ precursors in aqueous solution. $\mathrm{PdCu}$ NDs demonstrate enhanced peroxidase-like activity compared to that of monometallic Pd nanomaterials. In particular, the peroxidaselike activities of $\mathrm{PdCu}$ NDs are further improved by tuning the molar ratio of $\mathrm{Pd} / \mathrm{Cu}$, as the $\mathrm{Cu}$ content regulates the surface $d$-electrons in a non-linear manner. The distinct peroxidase-like properties of the fine-tuned PdCu NDs endow them with excellent biofilm elimination capability via the generation of hydroxyl radicals. Our work offers great opportunity to design noble metal nanozymes with enhanced performance, which might advance the development of nanozymes as a new class of highly efficient antibacterial agents.

\section{Declarations}

\section{Acknoledgements}

This work was supported by National Natural Science Foundation of China (82171997, 31971320), Guangdong Basic and Applied Basic Research Foundation for Distinguished Young Scholars (2020B1515020027), the grant from Guangzhou Science and Technology Bureau (202002020070, 202102010181, 202102010007), Guangdong Science and Technology Department (2020B1212060018, 2020B1212030004), a project funded by the Priority Academic Program Development of Jiangsu Higher Education Institutions (PAPD), Jiangsu Provincial Key Laboratory of Radiation Medicine and Protection, the "Chemical Grid Project" of Beijing University of Chemical Technology. R.Z. also acknowledges the financial support from W. M. Keck Foundation (Grant award 2019-2022).

\section{Author information}

Guotao Yuan and Shitong Zhang contributed equally to the manuscript.

\section{Affiliations}

State Key Laboratory of Radiation Medicine and Protection, School for Radiological and Interdisciplinary Sciences (RAD-X), Collaborative Innovation Center of Radiation Medicine of Jiangsu Higher Education Institutions, Soochow University, Suzhou 215123, China

Guotao Yuan, Shitong Zhang, Zaixing Yang, Xin Tian \& Ruhong Zhou

Guangdong Provincial Key Laboratory of Malignant Tumor Epigenetics and Gene Regulation, Guangdong-Hong Kong Joint Laboratory for RNA Medicine, Medical Research Center, Sun Yat-Sen Memorial Hospital, Sun Yat-Sen University, Guangzhou 510120, China 
National Engineering Laboratory for Modern Silk, College of Textile and Clothing Engineering, Soochow University, Suzhou 215021, China

Si Cheng

Institute of Quantitative Biology, College of Life Sciences, Zhejiang University, Hangzhou 310058, China

Ruhong Zhou

Department of Chemistry, Columbia University, New York, NY 10027, United States

Ruhong Zhou

\section{Contribitions}

$\mathrm{XT}, \mathrm{YP}$ and RZ designed the research. GY, SZ, ZY and SC conducted the experiments, statistical analysis, and data interpretation. $\mathrm{XT}, \mathrm{GY}, \mathrm{SZ}$ and $\mathrm{RZ}$ contributed to writing and assisted in editing the manuscript. All authors read and approved the final manuscript.

\section{Corresponding authors}

Correspondence to Xin Tian, Yue Pan or Ruhong Zhou.

Ethics approval and consent to participate

Not applicable.

\section{Consent for publication}

Not applicable.

\section{Competing interests}

The authors declare that they have no competing interests.

\section{Supplementary Information}

\section{Additional file 1:}

Table S1: Comparison of the kinetic parameters of various catalysts toward the oxidation of TMB by $\mathrm{H}_{2} \mathrm{O}_{2}$. Figure $\mathrm{S} 1$. UV-vis spectroscopy of samples containing $T M B, \mathrm{H}_{2} \mathrm{O}_{2}$, and $\mathrm{Pd}_{9.2} \mathrm{Cu} \mathrm{NDs}$ in acetate buffer ( $\mathrm{pH}$ 3.6) for $10 \mathrm{~min}$. Figure S2. Effects of $\mathrm{pH}$ and temperature on peroxidase-like activity of $\mathrm{Pd}_{9.2} \mathrm{Cu}$ NDs. Figure S3. Adsorptions of $\mathrm{H}_{2} \mathrm{O}_{2}$ on $\mathrm{Pd}_{11.5} \mathrm{Cu}$ (111) surface at $\mathrm{Pd}$-top and Cu-top sites with two typical orientations. Figure S4. Hirshfeld charge analysis on the PdCu slab models with different $\mathrm{Pd} / \mathrm{Cu}$ 
ratios. Figure. S5. (a) The EP of $\mathrm{Pd}_{11.5} \mathrm{Cu}$ slab model (white, $\mathrm{H}$; red, O; cyan, $\mathrm{Pd}$ ). (b) The separately scanned EP of $\mathrm{Pd}_{11.5} \mathrm{Cu}, \mathrm{Pd}_{6.7} \mathrm{Cu}$ and $\mathrm{H}_{2} \mathrm{O}_{2}$ along the path denoted in panel (a). Figure S6. The lowestenergy adsorption structures for the coadsorption of two $\cdot \mathrm{OH}$ on $\mathrm{PdCu}$ bimetallic surface on $\mathrm{Pd}_{11.5} \mathrm{Cu}$.

\section{References}

[1] Gao, L.; Liu, Y.; Kim, D.; Li, Y.; Hwang, G.; Naha, P. C.; Cormode, D. P.; Koo, H. J. B., Nanocatalysts promote streptococcus mutans biofilm matrix degradation and enhance bacterial killing to suppress dental caries in vivo. Biomaterials 2016, 101, 272-284.

[2] Wang, J.; Cooper, D. L.; Zhan, W.; Wu, D.; He, H.; Sun, S.; Lovett, S. T.; Xu, B., Diglycine enables rapid intrabacterial hydrolysis for activating anbiotics against gram-negative bacteria. Angew. Chem. Int. Ed. 2019, 131, 10741-10744.

[3] Ji, S.; Jiang, B.; Hao, H.; Chen, Y.; Dong, J.; Mao, Y.; Zhang, Z.; Gao, R.; Chen, W.; Zhang, R.; Liang, Q.; Li, H.; Liu, S.; Wang, Y.; Zhang, Q.; Gu, L.; Duan, D.; Liang, M.; Wang, D.; Yan, X.; Li, Y., Matching the kinetics of natural enzymes with a single-atom iron nanozyme. Nat. Catal. 2021, 4, 407-417.

[4] Hall-Stoodley, L.; Costerton, J. W.; Stoodley, P. J., Bacterial biofilms: from the natural environment to infectious diseases. Nat. Rev. Microbiol. 2004, 2, 95-108.

[5] Imaizumi, T.; Tran, H. G.; Swartz, T. E.; Briggs, W. R.; Kay, S., FKF1 is essential for photoperiodic-specific light signalling in Arabidopsis. Nature 2003, 426, 302-306.

[6] Banin, E.; Vasil, M. L.; Greenberg, E. P., Iron and Pseudomonas aeruginosa biofilm formation. P. Natl. Acad. Sci. USA 2005, 102, 11076-11081.

[7] Lok, C.-N.; Ho, C.-M.; Chen, R.; He, Q.-Y.; Yu, W.-Y.; Sun, H.; Tam, P. K.-H.; Chiu, J.-F.; Che, C.-M., Silver nanoparticles: partial oxidation and antibacterial activities. J. Biol. Inorg. Chem. 2007, 12, 527-534.

[8] Khatami, M.; Heli, H.; Jahani, P. M.; Azizi, H.;Nobre, M. A. L., Copper/copper oxide nanoparticles synthesis using Stachys lavandulifolia and its antibacterial activity. IET Nanobiotechnol. 2017, 11, 709713.

[9] Liu, S.; Zeng, T. H.; Hofmann, M.; Burcombe, E.; Wei, J.; Jiang, R.; Kong, J.; Chen, Y., Antibacterial activity of graphite, graphite oxide, graphene oxide, and reduced graphene oxide: membrane and oxidative stress. ACS Nano 2011, 5, 6971-6980.

[10] Jiang, D.; Ni, D.; Rosenkrans, Z. T.; Huang, P.; Yan, X.; Cai, W., Nanozyme: new horizons for responsive biomedical applications. Chem. Soc. Rev. 2019, 48, 3683-3704.

[11] Kluenker, M.; Nawaz Tahir, M.; Ragg, R.; Korschelt, K.; Simon, P.; Gorelik, T. E.; Barton, B.; Shylin, S. I.; Panthöfer, M.; Herzberger, J., $\mathrm{Pd@Fe} \mathrm{O}_{3}$ superparticles with enhanced peroxidase activity by solution 
phase epitaxial growth. Chem. Mater. 2017, 29, 1134-1146.

[12] Wu, J.; Wang, X.; Wang, Q.; Lou, Z.; Li, S.; Zhu, Y.; Qin, L.; Wei, H., Nanomaterials with enzyme-like characteristics (nanozymes): next-generation artificial enzymes (II). Chem. Soc. Rev. 2019, 48, 1004-1076.

[13] Zheng, X.; Liu, Q.; Jing, C.; Li, Y.; Li, D.; Luo, W.; Wen, Y.; He, Y.; Huang, Q.; Long, Y. T., Catalytic gold nanoparticles for nanoplasmonic detection of DNA hybridization. Angew. Chem. Int. Ed. 2011, 123, 12200-12204.

[14] Pratsinis, A.; Kelesidis, G. A.; Zuercher, S.; Krumeich, F.; Bolisetty, S.; Mezzenga, R.; Leroux, J.-C.; Sotiriou, G. A., Enzyme-mimetic antioxidant luminescent nanoparticles for highly sensitive hydrogen peroxide biosensing. ACS Nano 2017, 11, 12210-12218.

[15] Zhu, P.; Chen, Y.; Shi, J., Nanoenzyme-augmented cancer sonodynamic therapy by catalytic tumor oxygenation. ACS Nano 2018, 12, 3780-3795.

[16] Fan, K.; Xi, J.; Fan, L.; Wang, P.; Zhu, C.; Tang, Y.; Xu, X.; Liang, M.; Jiang, B.; Yan, X., In vivo guiding nitrogen-doped carbon nanozyme for tumor catalytic therapy. Nat. Comm. 2018, 9, 1-11.

[17] Yin, W.; Yu, J.; Lv, F.; Yan, L.; Zheng, L. R.; Gu, Z.; Zhao, Y., Functionalized nano-MoS 2 with peroxidase catalytic and near-infrared photothermal activities for safe and synergetic wound antibacterial applications. ACS Nano 2016, 10, 11000-11011.

[18] Ge, C.; Wu, R.; Chong, Y.; Fang, G.; Jiang, X.; Pan, Y.; Chen, C.; Yin, J., Synthesis of Pt hollow nanodendrites with enhanced peroxidase-like activity against bacterial infections: implication for wound healing. Adv. Funct. Mater. 2018, 28, 1801484.

[19] Adams, C. P.; Walker, K. A.; Obare, S. O.; Docherty, K. M., Size-dependent antimicrobial effects of novel palladium nanoparticles. Plos One 2014, 9, e85981.

[20] Wei, J.; Chen, X.; Shi, S.; Mo, S.; Zheng, N., An investigation of the mimetic enzyme activity of twodimensional Pd-based nanostructures. Nanoscale 2015, 7, 19018-19026.

[21] Fang, G.; Li, W.; Shen, X.; Perez-Aguilar, J. M.; Chong, Y.; Gao, X.; Chai, Z.; Chen, C.; Ge, C.; Zhou, R., Differential Pd-nanocrystal facets demonstrate distinct antibacterial activity against Gram-positive and Gram-negative bacteria. Nat. Comm. 2018, 9, 1-9.

[22] He, W.; Wu, X.; Liu, J.; Hu, X.; Zhang, K.; Hou, S.; Zhou, W.; Xie, S., Design of AgM bimetallic alloy nanostructures $(\mathrm{M}=\mathrm{Au}, \mathrm{Pd}, \mathrm{Pt})$ with tunable morphology and peroxidase-like activity. Chem. Mater. 2010, 22, 2988-2994.

[23] Zhang, H.; Jin, M.; Xiong, Y.; Lim, B.; Xia, Y., Shape-controlled synthesis of Pd nanocrystals and their catalytic applications. Acc. Chem. Res. 2013, 46, 1783-1794. 
[24] Boomi, P.; Prabu, H. G. J. C.; Physicochemical, S. A.; Aspects, E., Synthesis, characterization and antibacterial analysis of polyaniline/Au-Pd nanocomposite. Colloids Surf. A 2013, 429, 51-59.

[25] Lv, H.; Chen, X.; Xu, D.; Hu, Y.; Zheng, H.; Suib, S. L.; Liu, B., Ultrathin PdPt bimetallic nanowires with enhanced electrocatalytic performance for hydrogen evolution reaction. Appl. Catal. B: Environ. 2018, $238,525-532$.

[26] Xia, X.; Zhang, J.; Lu, N.; Kim, M. J.; Ghale, K.; Xu, Y.; McKenzie, E.; Liu, J.; Ye, H., Pd-Ir core-shell nanocubes: a type of highly efficient and versatile peroxidase mimic. ACS Nano 2015, 9, 9994-10004.

[27] Yan, Y.; Li, X.; Tang, M.; Zhong, H.; Huang, J.; Bian, T.; Jiang, Y.; Han, Y.; Zhang, H.; Yang, D., Tailoring the edge sites of 2D Pd nanostructures with different fractal dimensions for enhanced electrocatalytic performance. Adv. Sci. 2018, 5, 1800430.

[28] Chen, Y.; Fan, Z.; Zhang, Z.; Niu, W.; Li, C.; Yang, N.; Chen, B.; Zhang, H., Two-dimensional metal nanomaterials: synthesis, properties, and applications. Chem. Rev. 2018, 118, 6409-6455.

[29] Yang, N.; Zhang, Z.; Chen, B.; Huang, Y.; Chen, J.; Lai, Z.; Chen, Y.; Sindoro, M.; Wang, A.-L.; Cheng, H.; Fan, Z.; Liu, X.; Li, B.; Zong, Y.; Gu, L.; Zhang, H., Synthesis of ultrathin PdCu alloy nanosheets used as a highly efficient electrocatalyst for formic acid oxidation. Adv. Mater. 2017, 29, 1700769.

[30] Song, Y.; Yang, Y.; Medforth, C. J.; Pereira, E.; Singh, A. K.; Xu, H.; Jiang, Y.; Brinker, C. J.; van Swol, F.; Shelnutt, J. A., Controlled synthesis of 2-D and 3-D dendritic platinum nanostructures. J. Am. Chem. Soc. 2004, 126, 635-645.

[31] Huang, W.; Kang, X.; Xu, C.; Zhou, J.; Deng, J.; Li, Y.; Cheng, S., 2D PdAg alloy nanodendrites for enhanced ethanol electroxidation. Adv. Mater. 2018, 30,1706962.

[32] Jiang, B.; Duan, D.; Gao, L.; Zhou, M.; Fan, K.; Tang, Y.; Xi, J.; Bi, Y.; Tong, Z.; Gao, G., Standardized assays for determining the catalytic activity and kinetics of peroxidase-like nanozymes. Nat. Protoc. 2018, 13, 1506-1520.

[33] Bruno, E.; Ginatempo, B.; Giuliano, E. S., Fermi surface incommensurate nestings and phase equilibria in Cu-Pd alloys. Phys. Rev. B 2001, 63, 174107.

[34] Xu, W.; Zhu, S.; Liang, Y.; Cui, Z.; Yang, X.; Inoue, A.; Wang, H., A highly efficient electrocatalyst based on amorphous $\mathrm{Pd}-\mathrm{Cu}-\mathrm{S}$ material for hydrogen evolution reaction. J. Mater. Chem. A 2017, 5, 18793-18800.

[35] Khan, J. A.; He, X.; Shah, N. S.; Khan, H. M.; Hapeshi, E.; Fatta-Kassinos, D.; Dionysiou, D. D., Kinetic and mechanism investigation on the photochemical degradation of atrazine with activated $\mathrm{H}_{2} \mathrm{O}_{2}$, $\mathrm{S}_{2} \mathrm{O}_{8}{ }^{2-}$ and $\mathrm{HSO}_{5}{ }^{-}$. Chem. Eng. J. 2014, 252, 393-403. 
[36] Goldstein, A. S.; Beer, R. H.; Drago, R. S., Catalytic oxidation of hydrocarbons with $\mathrm{O}_{2}$ or $\mathrm{H}_{2} \mathrm{O}_{2}$ using a sterically hindered ruthenium complex. J. Am. Chem. Soc. 1994, 116, 2424-2429.

[37] Nørskov, J. K.; Bligaard, T.; Rossmeisl, J.; Christensen, C. H., Towards the computational design of solid catalysts. Nat. Chem. 2009, 1, 37-46.

\section{Figures}
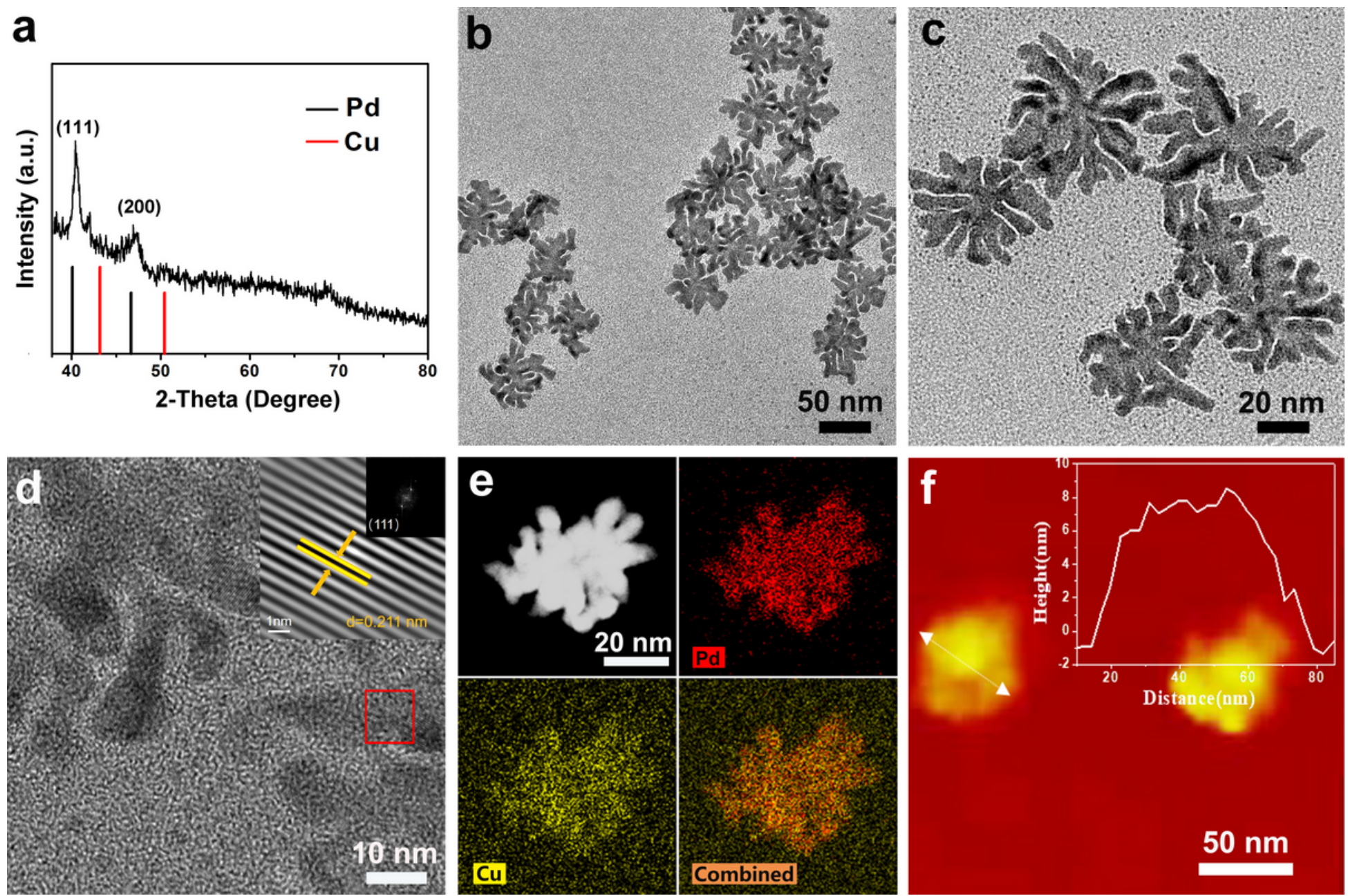

\section{Figure 1}

Structural characterization of 2D PdCu NDs. (a) XRD pattern. $(b, c)$ TEM images in two different scales, and (d) HRTEM image of PdCu NDs. The insert displays the lattice fringes in the red square area and the corresponding fast Fourier transform (FFT) pattern. (e) HAADF-STEM image and corresponding elemental mapping of a PdCu ND. (f) AFM image and corresponding height profile across a PdCu ND. 


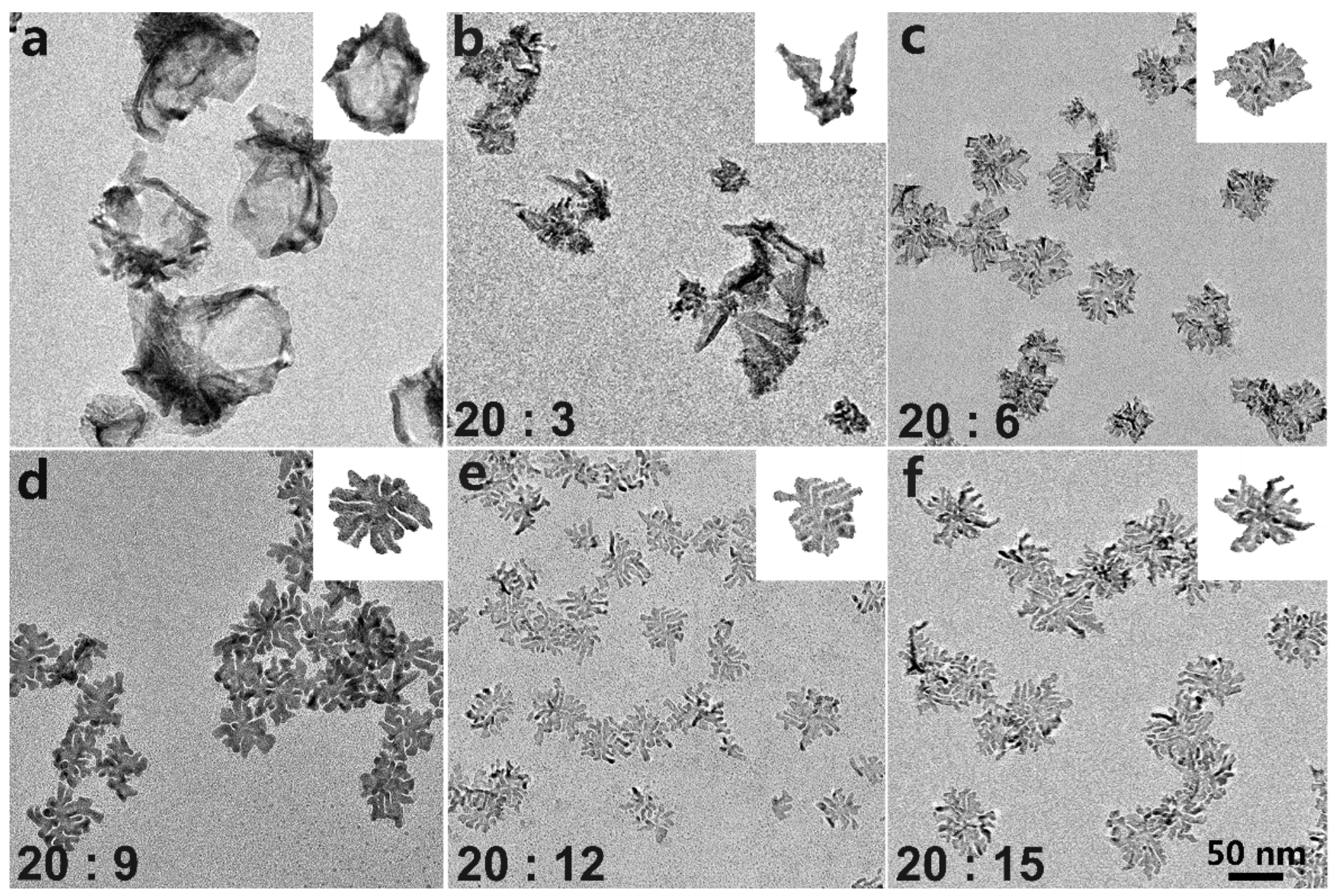

Figure 2

TEM images of samples with different molar ratios of $\mathrm{Pd}$ to Cu precursors. (a) $\mathrm{Pure} \mathrm{H}_{2} \mathrm{PdCl}_{4}$ formed $\mathrm{Pd}$ nanostructures. (b-f) PdCu nanostructures with molar ratios of $P d$ to Cu precursors were 20:3, 20:6, 20:9, $20: 12$, and 20:15, respectively.

\section{Figure 3}

Effect of $\mathrm{Cu}$ content on the peroxidase-like catalytic efficiency of PdCu nanostructures. (a) Reaction-time curves of TMB colorimetric reaction catalyzed by PdCu nanostructures with different molar ratios of Pd to $\mathrm{Cu}$. (b) Steady-state kinetic assays of peroxidase-like activity of PdCu nanostructures with varying concentrations of $\mathrm{H}_{2} \mathrm{O}_{2}$. (c) A line chart comparing the $k_{\text {cat }}$ and $K_{\mathrm{m}}$ values of different PdCu nanostructures. (d) The fluorescence spectra for detection of $\cdot \mathrm{OH}$ from the different reaction systems. 

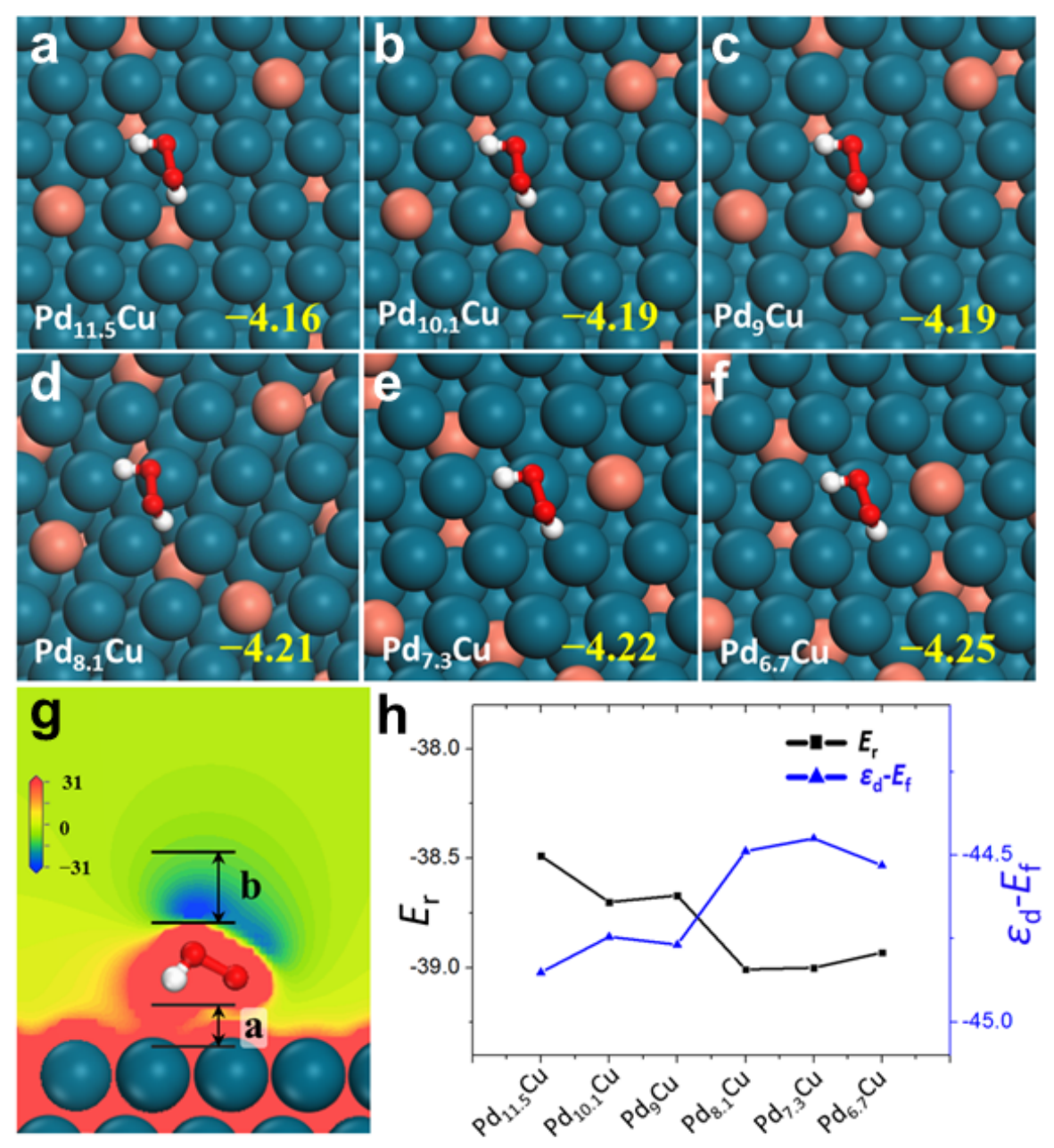

Figure 4

(a-f) Adsorption of $\mathrm{H}_{2} \mathrm{O}_{2}$ on $\mathrm{PdCu}$ nanocrystals surfaces ( $\mathrm{Pd} / \mathrm{Cu}$ ratio ranging from 6.7 to 11.5) with $E_{\text {ads }}$ in yellow text. (g) The EP of $\mathrm{H}_{2} \mathrm{O}_{2}$ adsorbed on $\mathrm{Pd}_{11.5} \mathrm{Cu}$ nanocrystals (white, $\mathrm{H}$; red, $\mathrm{O}$; cyan, $\mathrm{Pd}$ ). (h) The calculated $E_{\mathrm{r}}$ values for the dissociative adsorption of $\mathrm{H}_{2} \mathrm{O}_{2}$ on nanocrystals surface with different $\mathrm{Pd} / \mathrm{Cu}$ ratios (black line) and the $\varepsilon_{\mathrm{d}}-E_{\mathrm{f}}$ of the surfaces of the $\mathrm{PdCu}$ nanocrystals (blue line). The unit of energy is

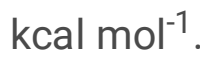



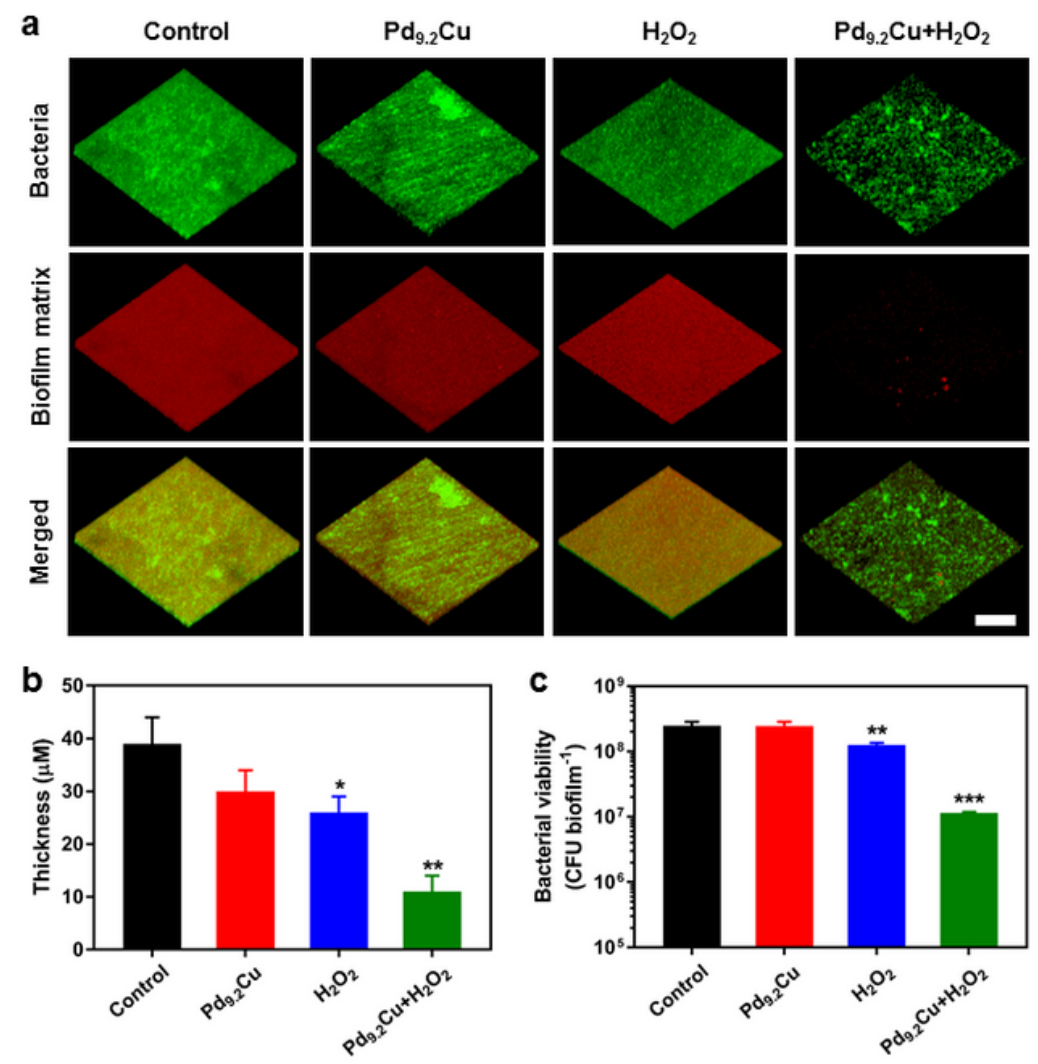

\section{Figure 5}

Biofilm disruption after treatments with $\mathrm{Pd}_{9.2} \mathrm{Cu} N D s$ and/or $\mathrm{H}_{2} \mathrm{O}_{2}$. (a) Confocal 3D images of $P$. aeruginosa biofilms treated by $\mathrm{Pd}_{9.2} \mathrm{Cu} N D s, \mathrm{H}_{2} \mathrm{O}_{2}$, or both. Scale bar $=100 \mu \mathrm{m}$. (b) Bar graph of a quantified thickness of biofilms analyzed from the z-stack images for each group. (c) The colony-forming units of $P$. aeruginosa cells in biofilms after different treatment conditions. Data are shown as mean \pm s.d. ${ }^{\star} p<0.05$ (vs. control); ${ }^{\star \star} p<0.01$ (vs. control); ${ }^{\star \star \star} p<0.001$ (vs. control).

\section{Supplementary Files}

This is a list of supplementary files associated with this preprint. Click to download.

- GraphicalAbstract.docx

- SupportingInformation.docx 